\title{
Effect of the glass-crystalline bond microstructure on the cutting ability of grinding wheels with $\mathrm{AL}_{2} \mathrm{O}_{3}$ abrasive grains
}

Daniela HERMAN, Krzysztof NADOLNY, Elżbieta SOCHA, Dawid ŚCIBIORSKI

DOI: 10.30464/jmee.2019.3.3.207

Cite this article as:

Herman D., Nadolny K., Socha E. Effect of the glass-crystalline bond microstructure on the cutting ability of grinding wheels with $\mathrm{AL}_{2} \mathrm{O}_{3}$ abrasive grains. Journal of Mechanical and Energy Engineering, Vol. 3(43), No. 3, 2019, pp. 207-214.

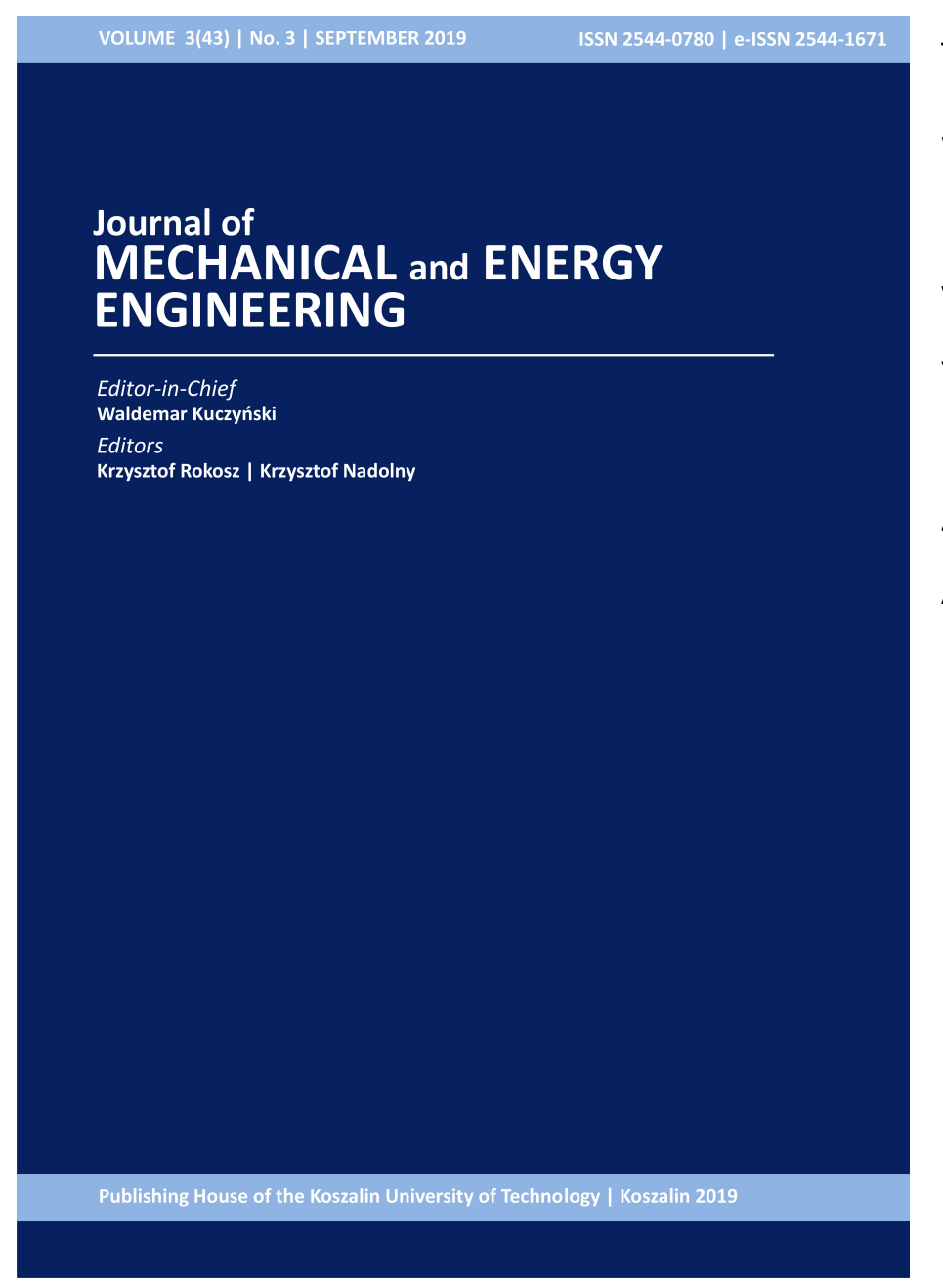

Journal of Mechanical and Energy Engineering

Website: jmee.tu.koszalin.pl

ISSN (Print): 2544-0780

ISSN (Online): 2544-1671

Volume: 3(43)

Number: 3

Year: 2019

Pages: 207-214

Article Info:

Received 15 September 2019

Accepted 23 October 2019

\section{Open Access}

This article is distributed under the terms of the Creative Commons Attribution 4.0 (CC BY 4.0) International License (http://creativecommons.org/licenses/by/4.0/), which permits unrestricted use, distribution, and reproduction in any medium, provided you give appropriate credit to the original author(s) and the source, provide a link to the Creative Commons license, and indicate if changes were made. 


\title{
EFFECT OF THE GLASS-CRYSTALLINE BOND MICROSTRUCTURE ON THE CUTTING ABILITY OF GRINDING WHEELS WITH $\mathrm{Al}_{2} \mathrm{O}_{3}$ ABRASIVE GRAINS
}

\author{
Daniela HERMAN ${ }^{1 *}$, Krzysztof NADOLNY², Elżbieta SOCHA ${ }^{3}$, Dawid ŚCIBIORSKI ${ }^{4}$ \\ ${ }^{1 *}$ Faculty of Mechanical Engineering, Department of Technical Physics and Nanotechnology, Koszalin \\ University of Technology, Racławicka 15-17, 75-620 Koszalin, Poland, \\ e-mail: daniela.herman@tu.koszalin.pl \\ ${ }^{2}$ Faculty of Mechanical Engineering, Department of Production Engineering, Koszalin University \\ of Technology, Racławicka 15-17, 75-620 Koszalin, Poland, e-mail: krzysztof.nadolny@tu.koszalin.pl \\ ${ }^{3}$ R\&D Department, Andre Abrasive Articles Sp. z o.o. Sp. k., Przemysłowa 10, 62-600 Koło, Poland, \\ e-mail: elzbieta.socha@andre.com.pl \\ ${ }^{3}$ R\&D Department, Andre Abrasive Articles Sp. z o.o. Sp. k., Przemysłowa 10, 62-600 Koło, Poland, \\ e-mail: dawid.scibiorski@andre.com.pl
}

(Received 15 September 2019, Accepted 23 October 2019)

\begin{abstract}
Standard ceramic abrasive tools are manufactured using glass bonds or mineral resources, in which the microstructure of the bonding bridges cannot be controlled. In this study, a new type of glass-crystalline bond was used to combine mixed abrasive grains from microcrystalline and monocrystalline corundum into an abrasive tool. The glass-crystalline bond has a fine crystalline structure (particle size of the crystalline phase: 1-1.5 $\mu \mathrm{m}$ ) and perfectly moistens the abrasive grains. This fact and the generated crystalline phase with a high coefficient of brittle fracture resistance enable the production of tools with a higher porosity and selfsharpening ability in comparison to grinding wheels with the use of industrial bond, which results in high performance indices with a longer service life.
\end{abstract}

Keywords: alumina grinding wheel, grinding performance, glass-ceramic vitrified bonds

\section{INTRODUCTION}

Among the important factors influencing the effectiveness of grinding with ceramic tools is the type of abrasive grain, ceramic bond and their microstructure. Properly selected parameters of processing of various materials allow to achieve the so-called effect of self-sharpening of ceramic abrasive tools in the grinding process, which at the same time guarantees high efficiency and surface quality of ground elements.

Although in the world's material processing technologies there is a clear trend towards grinding with tools made of CBN grains, the most important group are still abrasive tools made of conventional abrasives made of $\mathrm{Al}_{2} \mathrm{O}_{3}$. The emergence of new microcrystalline grades of numerous $\mathrm{Al}_{2} \mathrm{O}_{3}$ abrasive grits in recent years enables the development of new types of tools with different performance characteristics than those of conventional grit tools. Mechanical properties of the grains are very dependent on their microstructure [1-4], which proves that the production of required composite microstructures, especially with mixed grains, is still a challenge. The diversity of grain microstructures requires adjusting the microstructure of ceramic-mixed bonds to them, without which it is impossible to achieve high performance indices while maintaining high porosity of tools. Abrasive grains from $\mathrm{Al}_{2} \mathrm{O}_{3}$ (also from $\mathrm{CBN}$ ) are usually bonded with a glass bond, but in the new solutions they are gradually replaced with glass- 
crystalline materials or glasses containing various inclusions in the form of fine-dispersion phases or whiskers [5-9]. However, the scale of this effect depends on the volume share, morphology of the amplifying phase and its distribution in the amorphous residue.

The research results presented in this paper are a response to challenges posed to ceramic abrasive tools due to high mechanical strength and high porosity, obtained thanks to the possibility of manipulating the structure and microstructure of new glass-crystalline bonds.

\section{METHODOLOGY OF EXPERIMENTAL STUDIES}

The object of investigations were abrasive composites made of a mixture of abrasive grains of microcrystalline alumina Cubitron ${ }^{\mathrm{TM}}$ by $3 \mathrm{M}$ and monocorundum No. 10, as well as glass-crystalline numerous bonds from the glass-forming system $\mathrm{Al}_{0.107}$

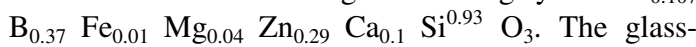
crystalline bond was obtained using a typical ceramic technology. The thermal history of the bond was observed in a high-temperature microscope by Leitz Wetzlar.

The ability to crystallize the material was determined by DTA method using a thermal analyzer of MOM Hungary company, adapted to work in air atmosphere from ambient temperature up to $1000^{\circ} \mathrm{C}$. A powdered sample of $0.8 \mathrm{~g}$ of the material was placed in an aluminium oxide crucible, using aluminium oxide as a reference material. The powdered sample was subjected to heat treatment in the temperature range of $20-1000^{\circ} \mathrm{C}$ at a constant speed of $\beta=5^{\circ} \mathrm{C} / \mathrm{min}$ in the full temperature range. Small flat grinding wheels of dimensions $35 \times 10 \times 10 \times 10 \mathrm{~mm}$ with the following characteristics were formed for the operational tests:

- 1×35×10×10-M3X100M5E01-50 - designated as No. 1 industrial grinding wheel,

- $1 \times 35 \times 10 \times 10$-M3X100M5VTHE-50 - designated as No. 4 - new bonded grinding wheel,

- $1 \times 35 \times 10 \times 10-$ M3X100J8VTHE-50 - designated as No. 10 new bonded grinding wheel.

Thermal treatment of the tools was carried out in the PK-4 chamber furnace in an air atmosphere at $940^{\circ} \mathrm{C}$ and held for 7 hours. The microstructure of thermally treated samples and digested in $10 \% \mathrm{HF}$ solution was observed using the scanning electron microscope JEOL-JSM-5500 LX Japan.

The aim of experimental investigations was to determine the influence of differences in the structure of small-dimensional flat grinding wheels with dimensions $35 \times 10 \times 10 \times 10 \mathrm{~mm}$ on the period of their durability and the quality of surface treated in the internal cylindrical grinding process.
Before the grinding the workpiece was preliminary ground and the tested grinding wheel was dressed with a single-grained diamond dresser of mass $Q_{d}=1.25 \mathrm{kt}$. Then the internal diameter of the ground ring was measured (using Links Brand 50-160 sensor diameter of accuracy $\pm 1 \mu \mathrm{m}$ ) and the external diameter of the grinding wheel (using VIS mmZb 25-50 micrometer of accuracy $\pm 1 \mu \mathrm{m})$. After grinding, the internal diameter of the workpiece and the external diameter of the grinding wheel were again measured in order to determine its volumetric wear $V_{s}$. Axial roughness profiles of the machined surface were also measured and on its basis the values of $R a$ parameter (arithmetic mean deviation of the roughness profile) in $\mu \mathrm{m}$ were determined. The measurements were taken at a measuring position equipped with a Hommel-Tester T8000 contact profilometer manufactured by Hommelwerke GmbH. Table 1 presents the characteristics of the applied grinding process conditions.

Tab. 1. Characteristics of grinding conditions

\begin{tabular}{ll}
\hline Process & $\begin{array}{l}\text { Reciprocal pheripheral internal cylindrical } \\
\text { grinding process }\end{array}$ \\
\hline $\begin{array}{l}\text { Grinding } \\
\text { machine }\end{array}$ & $\begin{array}{l}\text { Universal grinding machine RUP } 28 \mathrm{P} \text { by } \\
\text { Mechanical Works Tarnów SA }\end{array}$ \\
\hline $\begin{array}{l}\text { Dressing } \\
\text { parameters }\end{array}$ & $\begin{array}{l}\text { Dresser: single-grain diamond dressee with } \\
\text { mass } Q_{d}=1.25 \mathrm{kt}, n_{s d}=12000 \mathrm{rpm}, \\
v_{f d}=10 \mathrm{~m} / \mathrm{s}, a_{d}=0.0125 \mathrm{~mm}, i_{d}=12\end{array}$ \\
\hline $\begin{array}{l}\text { Grinding } \\
\text { parameters }\end{array}$ & $\begin{array}{l}v_{s}=50 \mathrm{~m} / \mathrm{s}, v_{w}=0.83 \mathrm{~m} / \mathrm{s}, q=60, \\
v_{f a}=20 \mathrm{~mm} / \mathrm{s}, a_{\text {etot }}=0.20 \mathrm{~mm}, t_{s}=150 \mathrm{~s},\end{array}$ \\
\hline & $\begin{array}{l}\text { Grinding fluid (coolant) was prepared as a } 5 \% \\
\text { aqueous oil solution Castrol Syntilo RHS and } \\
\text { was administered to the grinding zone by } \\
\text { flooding method }\end{array}$ \\
Coolant & $\begin{array}{l}\text { Internal surfaces of the bearing rings made of } \\
100 \mathrm{Cr} 6 \mathrm{steel}(63 \pm 2 \mathrm{HRC}), \text { internal diameter: } \\
d_{w}=40 \mathrm{~mm}, \text { width: } b_{w}=18 \mathrm{~mm}\end{array}$ \\
\hline Workpiece
\end{tabular}

After the end of tool life, microscopic observations of the grinding wheel active surfaces under investigation were made with the use of a digital measurement microscope type Dino-Lite Edge AM7915MZT from ANMO Electronics Co.

\section{RESULTS AND DISCUSSION}

The designed bond is characterized by very good fluidity, which allows to burn tools at low temperature, i.e. $940^{\circ} \mathrm{C}$. The change of contours of the binder sample is shown in Fig. 1.

In the thermal processing the bond undergoes the process of crystallization, according to the DTA curve, Fig. 2. 


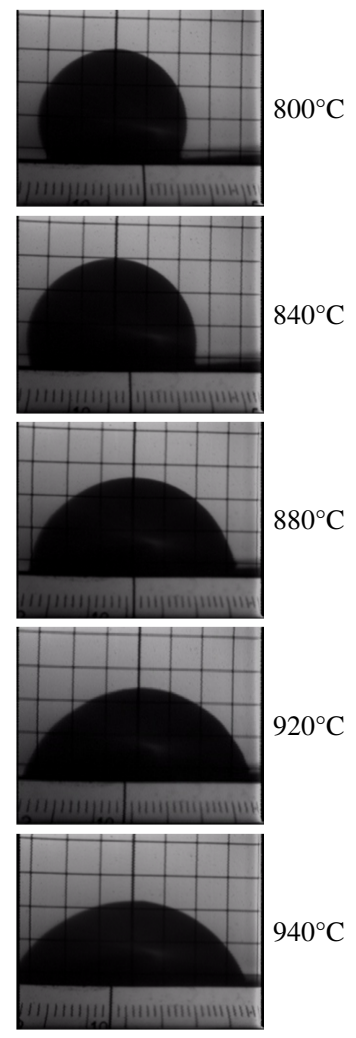

Fig. 1. Results of glass-crystalline bond observation in a high-temperature microscope

a)

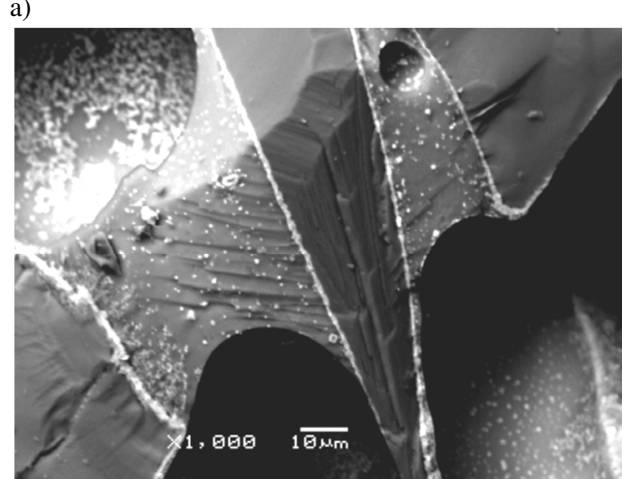

c)

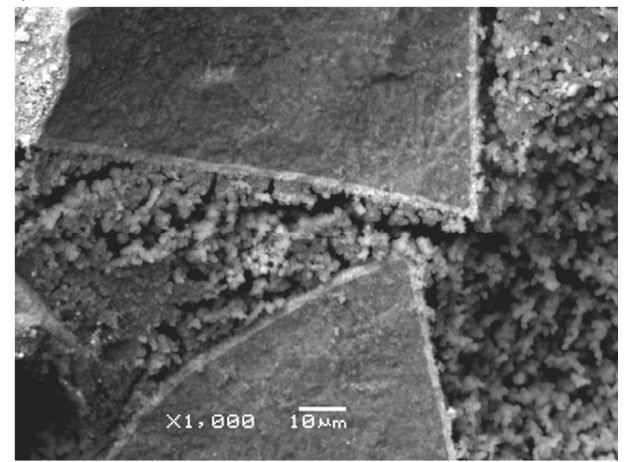

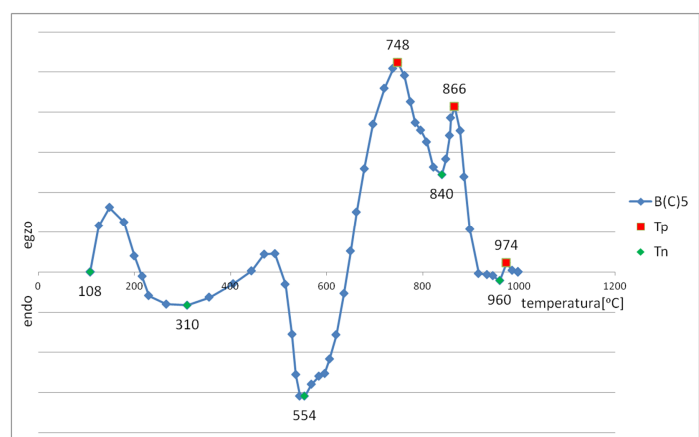

Fig. 2. DTA curve of the bond at $\beta=5^{\circ} \mathrm{C} / \mathrm{min}$

The obtained DTA curve is characterized by the occurrence of exothermic areas in the temperature range from approximately $550^{\circ} \mathrm{C}$ to $960^{\circ} \mathrm{C}$. The occurrence of two exothermic peaks indicates a complex mechanism of phase transformations occurring in the material, related to the process of crystallization of individual phases during heat treatment.

SEM analysis confirmed the presence of two different crystalline phases in the binding bridges (Fig. 3), belonging to the following type of structures $\mathrm{AB}_{2} \mathrm{O}_{4}$ i $\mathrm{AB}_{12} \mathrm{X}_{19}$.

Figure 4 presents a graph of changes in the value of grinding power gain $\Delta P$ in the durability period for the grinding wheels under investigation.

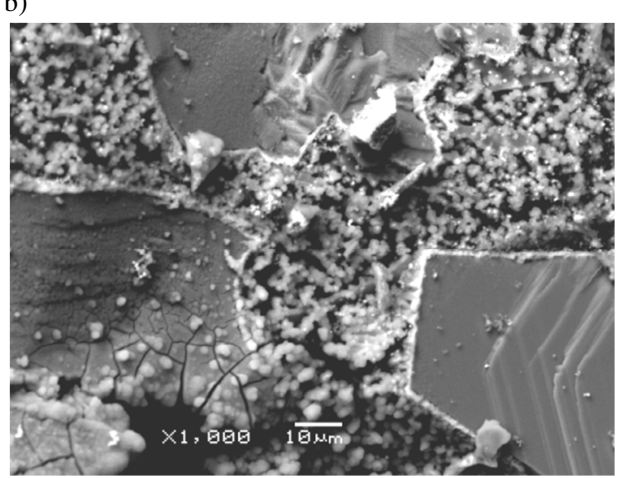

d)

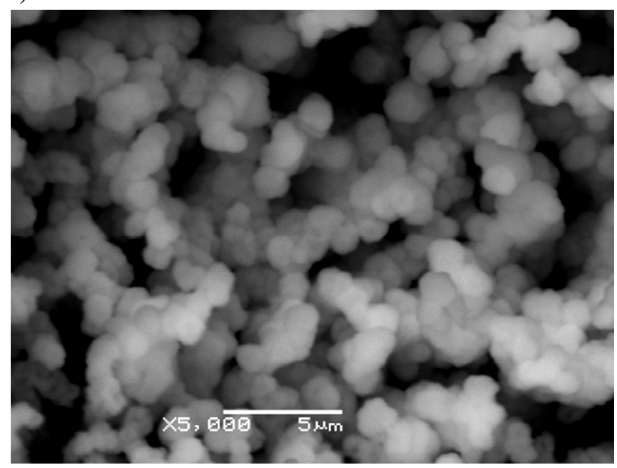

Fig. 3. SEM micrography of abrasive tool breakthroughs facricated at $940^{\circ} \mathrm{C}$ : a) unsealed bond bridges; b) etched bond bridge in monocorundum wheel; c) etched bond bridge in microcrystalline aluminium oxide wheel; d) bond microstructure 




Fig. 4. Diagram of changes in the value of grinding power gain $\Delta P$ during the durability period of the tested grinding wheels

Figure 5 presents a graph of changes in the value of the grinding wheel diameter $d_{s}$ during the durability period for the investigated grinding wheels.

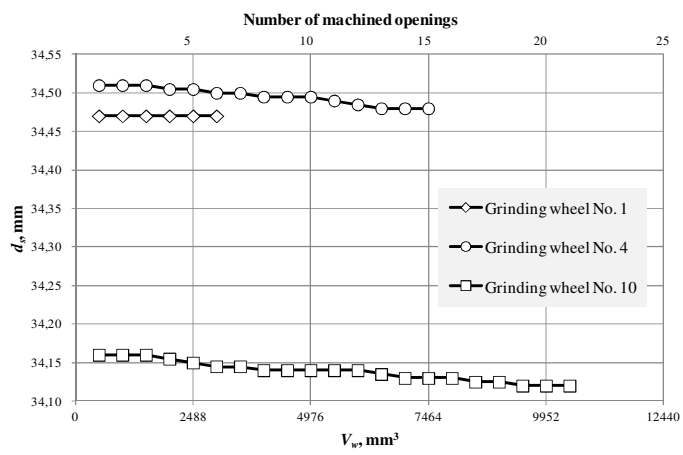

Fig. 5. Diagram of changes in the value of the grinding wheel diameter $d_{s}$ in the durability period for the tested grinding wheels

Comparison of the obtained results (Figs. 4 and 5) shows that in the process of grinding bearing rings carried out in the same conditions for each of the tested grinding wheels, the cutting capacity of the wheel No. $10\left(V_{w}=10450 \mathrm{~mm}^{3}\right)$ has been maintained for the longest time. The wheel No. 4 $\left(V_{w}=7464 \mathrm{~mm}^{3}\right)$ worked for about $25 \%$ less time. Both tools were characterized by non-standard bond microstructure. Reference wheel No. 1 (used in industry) lost its cutting ability in the adopted grinding process conditions during the sixth ring machining $\left(V_{w}=2986 \mathrm{~mm}^{3}\right)$, which means that the material removed by it constituted $28.6 \%$ and $40.0 \%$, respectively, in relation to grinding wheel No. 10 and No. 4.

Figure 6 presents a graph of changes in the $R a$ parameter value describing the geometric structure of the surface of machined workpieces and Figure 7 presents its average values determined on the basis of the results of measurements from the whole durability period of the tested grinding wheels.

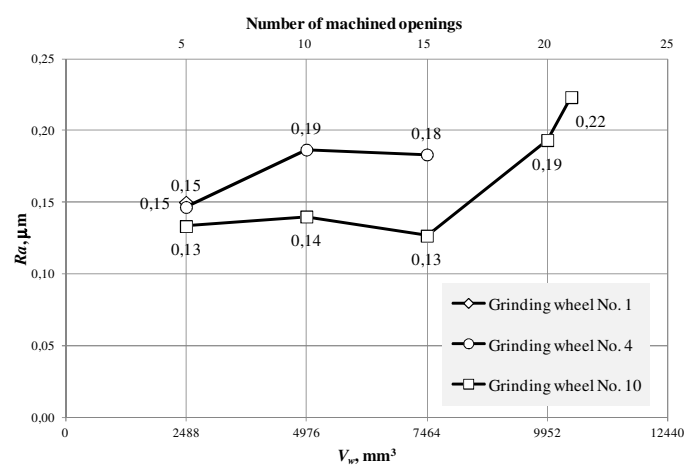

Fig. 6. Values of the Ra parameter describing the geometric structure of the surface of workpieces machined with the grinding wheels under investigation

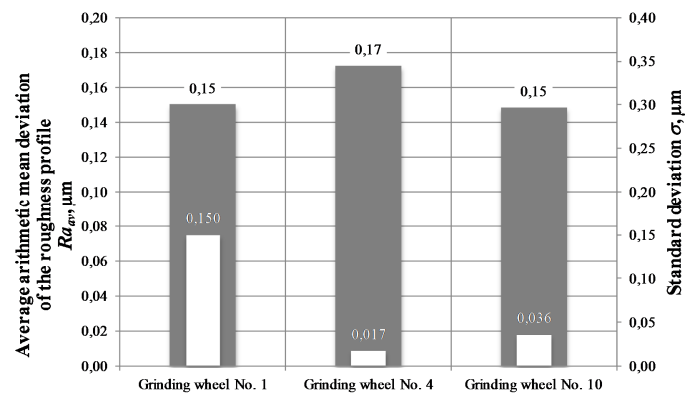

Fig. 7. Average values of $R a_{a v}$ parameter describing the geometric structure of machined parts surface determined on the basis of the results of measurements from the whole durability period of the tested grinding wheels

The surface roughness of machined workpieces expressed by $R a$ parameter was very similar for all evaluated grinding wheels. It ranged from $0.13 \mu \mathrm{m}$ to $0.22 \mu \mathrm{m}$ (Fig. 6), which is the correct value for the described machining process.

In Fig. 8-11 the average values of grinding power gain $\Delta P_{a v}$ (Fig. 8), grinding wheel volumetric wear $V_{s}$ (Fig. 9), material removal $V_{w}$ (Fig. 10) and grinding ratio $G$ (Fig. 11) determined on the basis of the results from the whole durability period of the tested grinding wheels are presented.



Fig. 8. Average values of the grinding power gain $\Delta P_{a v}$ calculated on the basis of the results from the whole durability period of the tested grinding wheels 


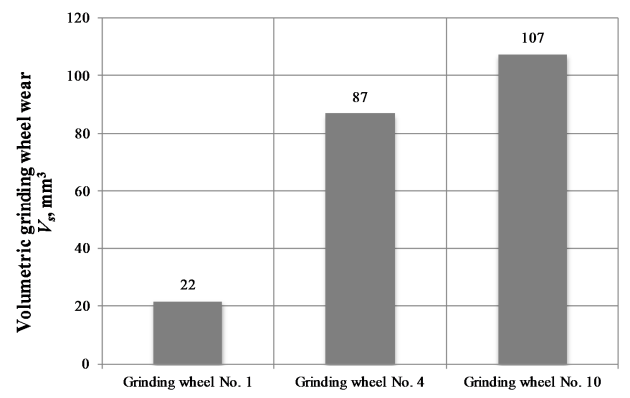

Fig. 9. Average values of volumetric wear of grinding wheel $V_{s}$ calculated on the basis of results from the whole durability period of the tested grinding wheels

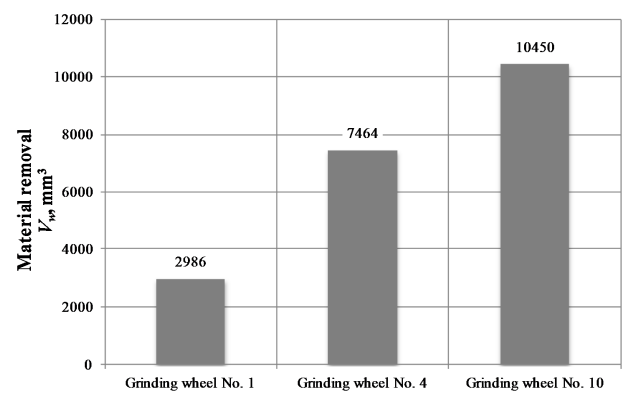

Fig. 10. Average values of material removal $V_{w}$ calculated on the basis of results from the whole durability period of the tested grinding wheels

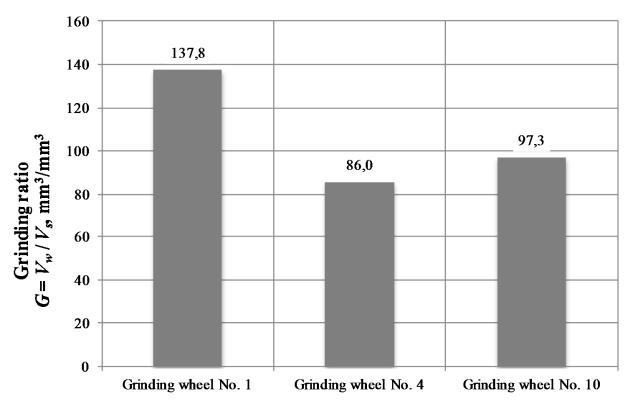

Fig. 11. Values of grinding ratio $G$ calculated on the basis of results from the whole durability period of the tested grinding wheels

In case of all three compared grinding wheels, comparable power consumption values during grinding were measured and their average values are within the range $\Delta P_{a v}=128-162 \mathrm{~W}$ (Fig. 8). It should be noted, however, that in case of grinding wheels No. 4 and No. 10 the average power values were $10 \%$ to $30 \%$ lower than during the reference operation of grinding wheel No. 1 (Fig. 8).

The biggest difference between the investigated grinding wheels was shown by the measurements of their volumetric wear $V_{s}$ (Fig. 9). It results from them that in the case of the reference wheel there was no phenomenon of gradual exposure of sharp cutting points of the abrasive grains by the bond, called in the literature as self-sharpening. It should be assumed that it was the ability of grinding wheels No. 4 and No. 10 to self-sharpen that enabled the correct execution of the machining process in a much longer time of their operation and as a result the removal of a much larger volume of processed material (Fig. 10). At the same time it translated into increased (in relation to reference wheel No. 1) volumetric wear shown in Fig. 9.

Grinding ratio $G$ determines the ratio of material removal $V_{w}$ to the volumetric wear of grinding wheel $V_{s}$, which is a very good measure of grinding wheel efficiency and utilization of the cutting potential of the abrasive grains contained in it. Comparison of the $G$-values presented in Fig. 11 shows about 40\% advantage of the reference wheel (wheel No. 1) in comparison with the values determined for wheels with modified microstructure of the bond (wheel No. 4 and No. 10). It results from a slight volumetric wear of grinding wheel No. 1 resulting mainly from dulling of active abrasive grain vertexes. As a result, no new sharp corners of the abrasive grains were exposed and the grinding wheel lost its cutting ability after machining 6 workpieces.

Figure 12 presents microscopic images of active surfaces of grinding wheels recorded during and after grinding using digital measuring microscope type Dino-Lite Edge AM7915MZT from ANMO Electronics Co. The views of grinding wheel surfaces before operation (Fig. 12a, 12c and 12e) prove very high porosity of grinding wheels, which is particularly important in the case of the grinding process of internal cylindrical surfaces, where there is a long zone of contact between the wheel and the workpiece, which significantly hinders the evacuation of chips from the grinding zone and the delivery of coolants.

The analysis of microscopic images recorded after grinding is completed (Fig. 12b, 12d and 12e) shows the highest share of blunted abrasive grains on the active surface of grinding wheel No. 1 (Fig. 12b). Moreover, on the surface of this wheel the intergranular spaces were filled with grinding products, including mainly chips. This phenomenon is very unfavorable from the point of view of stability and repeatability of the grinding process results.

The obtained effect of extending the service life of the designed grinding wheels in comparison to the reference (industrial) grinding wheel is the result of using a new type of glass-crystalline bond. The presence of spherical inclusions $\left(\mathrm{AB}_{11} \mathrm{X}_{19}\right.$ - where $\mathrm{A}$ : $\mathrm{La}, \mathrm{Y}, \mathrm{Mg}$; $\mathrm{B}$ : $\mathrm{Al}, \mathrm{X}-\mathrm{O}$ ) dispersed in the amorphous residue in the bond bridges results in obtaining higher isotropic properties of grinding wheel, while the second crystalline phase $\left(\mathrm{AB}_{2} \mathrm{O}_{4},-\right.$ where $\mathrm{A}: \mathrm{Zn}, \mathrm{Mg}$, $\mathrm{Fe}$; $\mathrm{B}$ : Al) concentrates mainly in the abrasive grain area. This layer, with the spinel structure, has a similar 
thermal expansion coefficient to the abrasive grain $7,5 \cdot 10^{-6} \mathrm{~K}^{-1}$ for $\mathrm{Al}_{2} \mathrm{O}_{3}[10]$ and $8.7-9.9 \cdot 10^{-6} \mathrm{~K}^{-1}$ for $\mathrm{ZnAl}_{2} \mathrm{O}_{4}$ [11]. Therefore, unfavourable thermomechanical stresses are minimized in the transition zone between the abrasive grain and the glass-crystalline bond and in the bond ( $\left.\alpha_{\text {inclusion }}=8.49 \cdot 10^{-6} \mathrm{~K}^{-1}\right)$ [12] Moreover, for spherical inclusions the residual thermal stresses are described by hydrostatic stress state $\left(\sigma_{11}=\sigma_{22}=\sigma_{33}\right)$ [13]. A favourable system of residual thermal stresses in the bond is determined, because the amorphous residue is in the state of compressive stresses in relation to spherical inclusions. This is confirmed by the coefficient of thermal expansion of amorphous phase residues in the bond bridge calculated by the authors (according to Wilkelman and Scott [14]), which amounts to $4.7410^{-6} \mathrm{~K}^{-1}$, which

a)

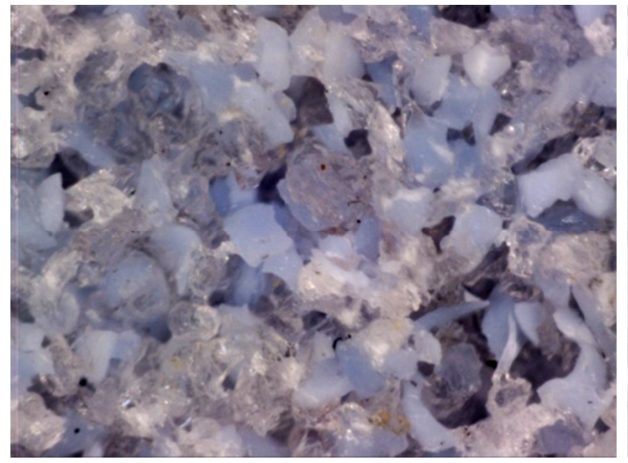

c)

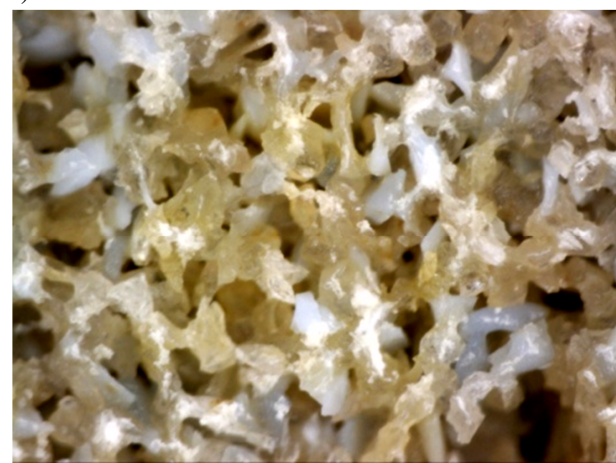

e)

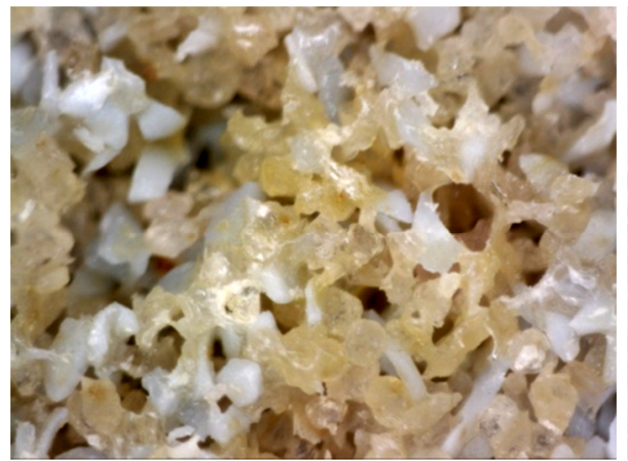

increases the mechanical strength of tools. The mechanism of grain cracking is mainly based on the course of grain cracking gap (visible surfaces after decohesion in Fig. 2) and not along the grain-bond boundary. The mechanism is also affected by high value of the coefficient of resistance to brittle fracture of spherical inclusions, which for the phase of similar chemical composition may reach the value of 4.6 $\mathrm{MPa} \cdot \mathrm{m}^{1 / 2}$ [15]. On the other hand, much lower $K_{I c}$ value for amorphous residue (standard values range from $0.5-0.6 \mathrm{MPa} \cdot \mathrm{m}^{1 / 2}[16]$ ) causes that cracks in the shape of meander are formed in it, omitting the spherical phase, which lengthens the path of the fracture. This translates into a strengthening of the tool.

b)



d)

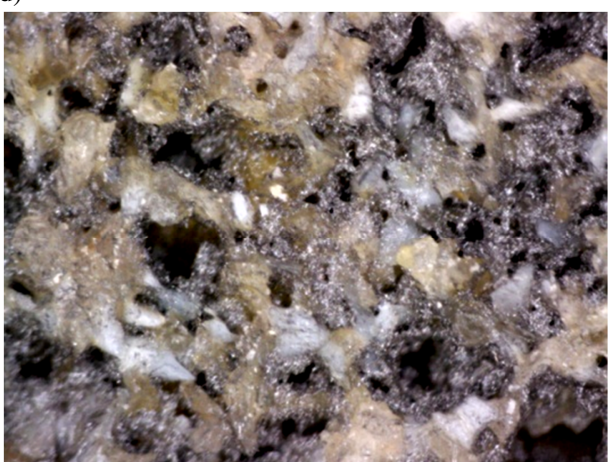

f)

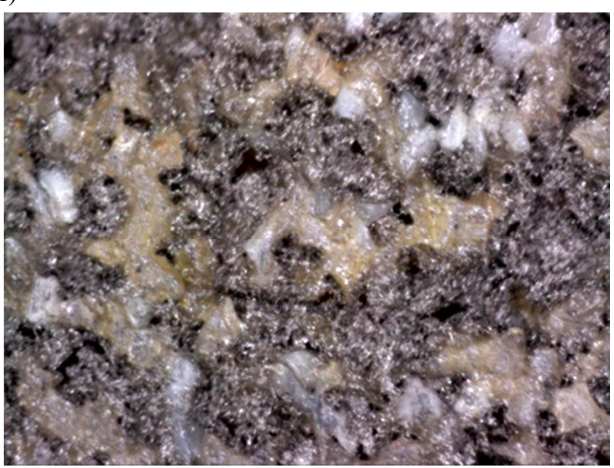

Fig. 12. Microscopic images of active surfaces of tested grinding wheels before (a, c, e) and immediately after the grinding process (b, d, f) - mag. 200x: a, b) grinding wheel No. 1; c, d) grinding wheel No. 4; e, f) grinding wheel No. 10 
At the same time, due to the microcrystalline structure of the bond, its microwear, which is largely compatible with the wear mechanism of abrasive grains, is possible. This has an impact on increasing the durability of a grinding wheel, especially for an open structure grinding wheel (volume of porous $V_{p}=42 \%$ and a small share of bond $V_{b}=12 \%$ ), which at the same time guarantees high (required) performance indices.

\section{CONCLUSIONS}

The designed glass-crystalline binder enables the production of tools from microcrystalline alumina and monocorundum with open structure and high selfsharpening ability. The tools can be fired at relatively low temperatures $\left(940^{\circ} \mathrm{C}\right)$. Thanks to the microcrystalline structure of the glass-crystalline binder, the micro-cutting process involves systematic (gradual) micro-crushing of grain and binder, which increases the tool life of the grinding wheel. Such a process is defined as self-sharpening and its occurrence in the grinding process is of decisive importance in obtaining repeatable machining results. In the case of designed grinding wheels, self-sharpening is initiated more easily and occurs in a much wider range of operating parameters.

\section{Acknowledgements}

This work was supported by the Polish Ministry of Science and Higher Education under Grant No. RPWP.01.02.00-30-0132/16 titled: Grinding wheels for highperformance grinding using a new generation of glasscrystalline ceramic bonds. The Authors wish to thank Mr. Stanisław Bokiej and Mr. Piotr Jaskólski from Laboratory of Mechanical Engineering for his help during experimental investigations of the grinding process, Mr. Krzysztof Maciejewski from the Laboratory of Metrology And Measurement Systems for stylus measurements as well as Mr. Ryszard Gritzman from Central Laboratory of the Institute of Technology and Education for acquisition of SEM micrographs.

\section{Nomenclature}

\section{Acronyms \\ CBN - Cubic Boron Nitride \\ DTA - Differential Thermal Analysis3 \\ GF - Grinding Fluid \\ SEM - Scanning Electron Microscopy}

\section{Symbols}

$a_{d} \quad$ - dressing allowance, $\mathrm{mm}$

$a_{e t o t .} \quad-$ total working engagement (machining allowance), $\mathrm{mm}$

$b_{w} \quad-$ workpiece diameter, $\mathrm{mm}$

$d_{s} \quad$ - grinding wheel outer diameter, $\mathrm{mm}$

$d_{w} \quad$ - workpiece diameter, $\mathrm{mm}$

$G \quad-$ grinding ratio, $\mathrm{mm}^{3} / \mathrm{mm}^{3}$

$i_{d} \quad-$ number of dressing passes



\section{References}

1. Zi-cheng Li, Zhi-hong Li , Ai-ju Zhang, Yu-mei Zhu, Influence of thermal treatment conditions on twodimensional crystal growth of nanocrystal corundum abrasives, Materials Research Bulletin 44 (2009) 762-767.

2. Wen Feng Ding \& Jiu Hua Xu \& Zhen Zhen Chen \& Hong Hua Su \& Yu Can Fu, Grain wear of brazed polycrystalline $\mathrm{CBN}$ abrasive tools during constant-force grinding Ti-6Al-4V alloy, Int J Adv Manuf Technol (2011) 52:969-976.

3. Frantisek Holesovsky, Michal Hrala, Integrity of ground cylindrical surface, Journal of Materials Processing Technology 153-154 (2004) 714-721.

4. Qing Miao, Wenfeng Ding, Yulong Gu, Jiuhua Xu, Comparative investigation on wear behavior of brown alumina and microcrystalline alumina abrasive wheels during creep feed grinding of different nickel-based superalloys, Wear 426-427 (2019) 1624-1634.

5. Jiang Shia, Feng He, Junlin Xie, Xiaoqing Liu, Hu Yang, Effects of $\mathrm{Na} 2 \mathrm{O} / \mathrm{BaO}$ ratio on the structure and the physical properties of low-temperature glass-ceramic vitrified bonds, Ceramics International 44 (2018) 10871-10877.

6. Xuezhi Wang, Zhelun Ma, Xue Sun, Tianbiao Yu, Wanshan Wang, Effects of $\mathrm{ZrO} 2$ and $\mathrm{Y} 2 \mathrm{O} 3$ on physical and mechanical properties of ceramic bond and ceramic CBN composites, International Journal of Refractory Metals \& Hard Materials 75 (2018) 18-24.

7. Dongdong Shan, Zhihong Li, Yumei Zhu, Hang Ye, Kai Gao, Yanyan $\mathrm{Yu}$, Influence of $\mathrm{TiO} 2$ on the physical properties of low-temperature ceramic vitrified bond and mechanical properties of CBN composites, Ceramics International 38 (2012) 4573-4578.

8. Baohui Zhao, Zhihong Li, Yumei Zhu, Effect of mullite particles on the mechanical strength and chemical durability of vitrified CBN composites, Composites: Part B 54 (2013) 265-268.

9. Baohui Zhao,ZhihongLi, YumeiZhu, Effect of polycrystalline mul lite fi bers on the properties of 
vitrified bond and vitrified CBN composites, Ceramics International 39 (2013) 2863-2868.

10. C.J. Engberg, E.H. Zehms, Thermal expansion of Al2O3, $\mathrm{BeO}, \mathrm{MgO}, \mathrm{B} 4 \mathrm{C}, \mathrm{SiC}$, and $\mathrm{TiC}$ above 1000 8C, J. Am. Ceram. Soc. 42 (1958) 300-305.

11. A. Petric, H. Lingw, Electrical conductivity and thermal expansion of spinels at elevated temperatures, J. Am. Ceram. Soc. 90 (2007)1515-1520.

12. Yuan-Hong Wang, Zhan-Guo Liu, Jia-Hu Ouyang, Hong-Zhi Liu, Ren-Xian Zhu, Preparation and thermophysical properties of LaMgAl11O19Yb3Al5O12 ceramic composites, Ceramics International 37 (2011) 2489-2493.

13. Chun-Hway, Hsuch, Paul F. Becher, Residual thermal stresses In ceramic composites. Part I: with ellipsoidal inclusions, Materials Science and Engineering A212 (1996) 22-28.

14. M.G. Rasteiro, Tiago Gassman, R. Santos, E. Antunes, Crystalline phase characterization of glass-ceramic Glazer, Ceramics International 33 (2007) 345-354

15. B. Jiang, M.H. Fang *, Z.H. Huang, Y.G. Liu, P. Peng, J. Zhang, Mechanical and thermal properties of LaMgAl11O19, Materials Research Bulletin 45 (2010) 1506-1508.

16. G.A. Gogotsin, Classification of ceramics and glass (edge chipping and fracture toughness), Ceramics International 40(2014)5591-5596.

\section{Biographical notes}

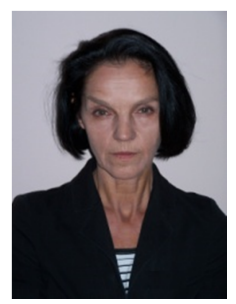

Daniela Herman is a research and teaching employee at the Department of Technical Physics and Nanotechnology at the Faculty of Mechanical Engineering of the Koszalin University of Technology. In 1976 she completed her master's degree in Materials Engineering, in 1984 she defended her doctoral dissertation at the Wrocław University of Technology. In 2005 she received her D.Sc. degree at the Koszalin University of Technology. Scientific research conducted by Daniela Herman concerns the design and manufacture of glass-crystalline materials with required properties, mainly used in hard and super-hard porous abrasive composites. He is the author or co-author of 2 monographs, 8 chapters in book publications, 78 publications, 8 patents and has participated in 25 research projects.

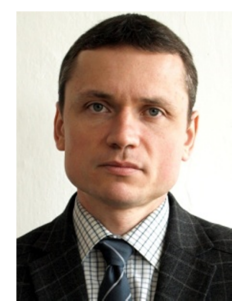

Krzysztof Nadolny received his M.Sc. degree in Mechanics and Machine Design and next Ph.D. (with honors) as well as D.Sc. degree in Machinery Construction and Operation from Koszalin University of Technology, in 2001, 2006 and 2013, respectively. Since 2006 he has been a researcher in the Department of Production Engineering at the Koszalin University of Technology and in 2019 he became head of this department. His scientific interests focus on problems concerning machining processes and tools, efficiency, monitoring and diagnostics of machining processes as well as tribology. He has participated in 2 international and 4 national research projects, presenting results of his work at 16 international and 29 national conferences, published more than 220 scientific papers in international and national journals, book chapters, as well as conference proceedings. $\mathrm{He}$ is also the author of 6 monographs and 13 national patents.

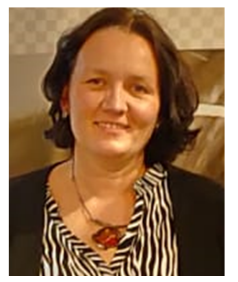

Elżbieta Socha received her M.Sc. degree and Ph.D. degree in Technology of Chemistry from the Poznań University of Technology in 2000 and 2005 respectively. Since 2005 she has been the Head of Research and Development Department in Andre Abrasive Articles Sp. z o.o. Sp. k. . Her professional interests are focused on new raw materials, and on new methods of abrasive tool production with resin and vitrified bonds. She cooperates with many groups of researchers from main Polish Universities of Technology. She is a co-author of 6 scientific publications and 3 national patents. She has participated in 5 national research projects in the abrasive area including WRPO 1.2: "Grinding wheels for high-performance grinding using a new generation of glass-crystalline ceramic bonds".



Dawid Ścibiorski received his M. Sc. Eng. degree in Chemistry and Material Engineering in interdisciplinary studies conducted by Adam Mickiewicz University in Poznań, Military University of Technology in Warsaw and Łódź University of Technology in Łódz. He has been working in Andre Abrasive Articles as a R\&D Engineer since 2017. He is a Specialist R\&D Engineer in the Andre Abrasive Articles company since 2019 committing to improving bonded abrasive wheels based on resinoid and vitrified bonds. He completed post-graduate studies at the Warsaw University of Technology in 2019. Participant in project WRPO 1.2: "Grinding wheels for high-performance grinding using a new generation of glass-crystalline ceramic bonds". 